\title{
Cross-cultural variation in deliberate metaphor
}

\section{interpretation}

\author{
Andreas Musolff \\ University of East Anglia
}

The distinction between 'deliberate' and 'non deliberate' metaphors has been developed within a five-step framework (Steen) of metaphor production.

Deliberate metaphors invite the addressee to pay special attention to their crossdomain structure mapping rather than focusing primarily on the topical proposition. This paper presents results of a pilot survey eliciting interpretations for the metaphors A NATION IS A BODY/A NATION IS A PERSON from an international sample of respondents in 10 different countries. ESL/EFL users from diverse cultural and/or linguistic backgrounds were asked to apply the metaphorical idiom body politic to their home nations. The responses show systematic variation in preferred metaphor interpretations, some of which can be linked to dominant cultural traditions, as well as evidence of polemical and/or ironic elaboration. Neither of these findings is predicted by classic conceptualist models that describe metaphor understanding as an automatic and unconscious process. Instead, when paying special attention to metaphoricity, informants seem to have chosen between diverse interpretation versions and in some cases to have elaborated them further to achieve social pragmatic effects. These findings provide new supporting evidence for Deliberate Metaphor Theory by highlighting deliberateness in metaphor interpretation and outlining 
perspectives for further empirical testing of metaphor understanding in specific registers and usage contexts (e.g., political discourse, EFL/ESL acquisition).

Keywords: cross-cultural variation, deliberate/non-deliberate metaphor, English as a Second Language, English as a Lingua Franca, metaphor, metonymy, political discourse

\section{Introduction: An unexpected exercise outcome}

The closely related but not identical conceptual metaphors of NATION-AS-BODY and NATIONAS-PERSON are grounded in the most immediately accessible source domain imaginable, namely speakers' own bodies and personalities, and have thus been deemed universal or nearuniversal (Chilton \& Lakoff, 1995, pp. 38-39; Kövecses, 2002, pp. 129-130). Despite this, there is prima facie evidence of culture-specificity for one of their most prominent linguistic manifestations, e.g. the lexicalised phrase body politic in English. Its morphological composition with postponed adjective part marks it as an archaic construction based on a loan translation from medieval Latin corpus politicum into the European vernacular languages in the late $15^{\text {th }}$ early $16^{\text {th }}$ centuries (Musolff, 2010). Today, the phrase belongs to a field of clichéd metaphors in English that refer to politics in terms of parts and functions of human bodies/persons and is routinely used by British and American media and politicians. Applications of the metaphorical concepts of the NATION AS A BODY and/or PERSON in French, German and other European languages show differing usage patterns that relate to specific discourse traditions (Musolff, 2011). However, they also share basic aspects with the English version, which can be traced back to the beginnings of Western political thought in Greek, Biblical and Roman traditions of philosophy and theology (Charbonnel, 2010; Guldin, 2000; 
Hale, 1971), i.e. that the NATION-AS-BODY is hierarchically ordered and depends for its functioning on the cooperation of all of its parts, and that the NATION-AS-PERSON acts as a unitary agent. Are such connotations typical, one may ask, for the 'universal' meaning of the NATION-AS-BODY/ PERSON metaphors, or do they constitute a specific European ('Western') version?

When teaching Communication and Metaphor Theory classes to international MA students at the University of East Anglia (UEA) in 2011, I introduced the phrase body politic as an example of a metaphor and ran a brief exercise to check its take-up and interpretation by the students by asking them to apply it to their "home nation". A few students were British and American and could be assumed to be familiar with the phrase and main denotation, but the majority were other European as well as non-European nationals who relied on English as the Lingua Franca (ELF) of Higher Education, at varying levels of English-as-L2 (ESL) competence (with a minimum average entry score of 6.5 on the IELTS test). Here are eight exemplary responses (normalized for English spelling but otherwise left unchanged):

(1) Student A: The head of the body represents the Queen of England, as she is in charge of the whole country and she is royalty. The features of the head (eyes, nose, mouth and ears) represent the different official people, such as politicians, the Prime Minister, the Government. [English L1 informant]

(2) Student B: If one organ or part of the national body suffers, the whole body would suffer from fever. In other words, having a healthy body requires healthy parts. As a nation, a problem in one area of a country should attract the attention of the whole people in that country. [Arab L1 informant] 
(3) Student C: 2 Heads: Head of state is the king? - Not sure anymore! Head of government are [Prime Minister] Rajoy and the big banks' presidents. [Spanish L1 informant]

(4) Student D: The face: president and government; the brain: oligarchs, members of parliament (make all decisions in essence); the hands: official and unofficial local authorities (including mafia groups); the mouth: the media - controlled by the oligarchs/MPs (dictate political ideology). [Ukrainian L1 informant]

(5) Student E: Beijing: Heart and Brain, Shanghai: Face (economic center); Hong Kong and Taiwan: Feet; Tianjin: Hands (= army close to Beijing); Shenzhen: Eyes ( $=$ the first place open to the world). [Mandarin L1 informant]

(6) Student F: Beijing is the heart of China. [...] The railway is the throat of China. Shanghai is the economic backbone of China. Tsingtao is the skeleton of Shandong province. Shenzhen is the liver of China; Tiananmen is the eye of Beijing [...]. [Mandarin L1 informant]

(7) Student G: Beijing: brain (government); Shanghai: hug/arm (welcome to foreign people); Guangzhou: feet (keep China going); Hong Kong: face (familiar to everyone, representative); Taiwan: hair (we can live without hair but it is necessary for beauty). [Mandarin L1 informant]

(8) Student H: [...] Taiwan: potential disease (maybe one time we have to fight against it and occupy it); Tibet: stomach (sometimes you feel uncomfortable); 
The head of the government: hair (if one goes down, always some other one will grow up). [Mandarin L1 informant]

Instead of an expected 'random' distribution of answers reflecting individual students' levels of ESL/EFL competence and nationalities, these responses obviously fall into two distinct classes. The first four examples describe the institutional political system in terms of a body's health, anatomy and functioning. Responses (5) - (8), on the other hand, identify geographical places in China, plus the politically separate state of Taiwan, and link these places to parts of the human anatomy and their functions on the basis of analogies between parts of the human body and institutions or typical activities in the respective cities and provinces. They then associate these analogies with further explanations that depict the Chinese nation as a quasi-personal agent that presents a face to the outside world, hugs those who are friendly towards it and fights diseases.

The task of interpreting the phrase body politic was fulfilled successfully in all the above examples, but they evidently represent significantly contrasting mapping perspectives. The first four responses differ in their national target referents, but all adhere to the main structural mappings of the Western tradition of political philosophy mentioned above, i.e. hierarchical ordering, interdependence of all parts of the body as a condition for its functioning. Irrespective of their nationalities, the students who had provided these examples had all majored in English language and literature in their respective first degrees, and so may well have been familiar with body politic imagery in English political discourse. The Chinese students' responses, by contrast, presuppose a basic mapping that is not found in responses (1) - (4): GEOGRAPHICAL SHAPE OF NATION (CHINA) - ANATOMY OF A HUMAN BODY, salient parts of which are selected according to PLACE-FOR-POLITICAL INSTITUTION/ FUNCTION metonymies (e.g. Beijing: seat of government; Shanghai, Shenzen, Hong Kong : internationally relevant 
economic centres; Taiwan : politically separate island state; Tibet : province with outlawed separatist movement). These metonymies are in turn analogically associated with functional interpretations of prominent body-parts and organs that partly resemble the 'Western' ones, e.g., brain or heart as controlling the rest of the body, face, eyes, arms as oriented to the outside world, hair as a variable physical property. These second-order analogies are loaded with evaluative interpretations, e.g., in the depictions of Taiwan as one of China's feet (as essential parts of the nation's body), or as hair (beautiful but not necessary for survival), or as disease (to be combated). The main contrast between the two sets of responses lies in its cognitive construction, specifically the grounding of the basic source-target mapping. For the Chinese respondents, the geo-political metonymy serves as the foundation to construct the metaphor, whereas this is not the case for the 'Western' responses, which construe the abstract notion of the state as a functional whole in analogy with BODY/PERSON aspects. Of course, the 'evidence' from such a small set of responses cannot be sufficient to substantiate any meaningful explanatory hypothesis. In the following sections, I will explore the qualitative nature of this evidence and then adduce data from a larger survey. The aim is to provide a platform for further empirical research on metaphor understanding, specifically (i) on differences between the 'automatic' processing of metaphorical meanings and their deliberate, interpretive explanation and (ii) on the cultural specificity of the latter, insofar as systematic distribution patterns of such interpretations can be related to particular cultural traditions in conceptualising one's nation/national identity.

\section{Metaphor reception and interpretation}


To gauge the significance of the metaphor responses for metaphor understanding, it is necessary to reflect on their main characteristic as reflective answers to an explicit interpretation task. The respondents were instructed to apply the source concepts BODY and/or PERSON metaphorically to the target concept of NATION, with the "home nation" reference providing the only explicit room for variation. Such a task is different from those set in experimental investigations of metaphor identification, processing or disambiguation, which aim to elucidate the implicit understanding of metaphor from a psycholinguistic perspective (see e.g., Gibbs, 1994; Gibbs \& Colston, 2012; Giora, 2003; Glucksberg, 2001). Instead, we asked the respondents to find an interpretive application of a newly introduced linguistic expression (and concept) that was overtly signalled as a metaphor to a familiar target domain (HOME NATION). Both the task and the responses therefore qualify as instances of what has been termed 'deliberate' metaphor, i.e. metaphorical language that invites the addressees to "set up a cross-domain mapping in their mental representation of the discourse in order to view one thing in terms of something else" (Steen, 2011b, p. 84).

The distinction between 'deliberate' and 'non deliberate' metaphors has been developed in the context of a 'Five Step model' of metaphorical meaning reconstruction that leads from initial metaphor identification to fully contextualised representation (Pragglejaz, 2007; Steen, 2008, 2009; Steen et al., 2010). The interest in deliberate metaphor provides a critical perspective on Conceptual Metaphor Theory's (CMT) dominant focus on 'unconscious', 'automatically' understood metaphors (Lakoff, 1993; Lakoff \& Johnson, 1980/2003) and was debated intensively in earlier issues of this journal (Gibbs, 2011a,b; Steen, 2011a,b; Deignan, 2011 and Müller, 2011). From the viewpoint of cognitive psycholinguistics, Gibbs criticised the notion of deliberate metaphor as not being "essentially different from other forms of metaphoric language" and "a methodological and theoretical idea without much substance” (Gibbs, 2011a, pp. 21, 49), whilst Steen’s, Deignan's and 
Müller's responses placed deliberateness of metaphor "at the heart of metaphor theory (Müller, 2011, p. 64) and located its place at the transition from the "Identification of open metaphorical comparison" (step 3 in the Five Step model) to "Identification of analogical structure" and of “cross-domain mapping” (steps 4 and 5) (Steen 2011b, pp. 93-97). Effectively, at stage 4, metaphor reception bifurcates between the hearer (or reader) attending to the source domain and becoming aware of "some form of discourse incongruity in the situation model" of their meaning representations (Steen, 2011b, p. 105), or in the case of non-deliberate metaphor, neglecting this incongruity and proceeding as quickly as possible to identifying a target proposition. Deliberate metaphor thus implies conscious analogyconstruction and cross-domain mapping.

In the class exercise reported above, the phrase body politic was explicitly introduced as a "metaphor" and as the object of an interpretative application task, so that there can be little doubt that the respondents' conscious attention was indeed focused on construing a conceptual bridge between source and target concepts to mediate their basic semantic incongruity. For the international students, the exercise amounted to a challenging task to make sense of a new, hitherto unknown expression in English as their L2/3 and/or Lingua Franca. Research on the use of figurative language in ESL and ELF contexts (Littlemore et al., 2011; MacArthur et al., 2013; Nacey, 2013; Philip, 2010; Piquer-Piriz, 2010; Wang \& Dowker, 2010) has provided ample evidence that wrongly understood metaphors are an obstacle to vocabulary acquisition and also an important factor in teacher-student miscommunication. In the case of our class-test, it would be too strong to speak of 'miscommunication'; after all, all responses made good sense as successful solutions of the exercise task (Musolff, 2014). Nevertheless, the students themselves articulated surprise about the differences. The contrasts in metaphor-metonymy combinations in particular indicated 
that they had worked out systematically differing perspectives, which asked for further exploration.

\section{Survey results of culture-specific interpretations of NATION-AS-BODY and NATION-AS- PERSON metaphors}

In order to increase the data basis as a first step towards such an investigation, the initial group of students and I developed a simple standardised questionnaire that asked informants to apply BODY/PERSON metaphors to their home nations and provide basic background information about first language, nationality, age and sex. This questionnaire (subsequently updated, see below) was administered in seven more UEA seminars and, with the generous help of colleagues and their students, in two other British universities and in Higher/ Further Education institutions of nine more countries (China, Germany, Hungary, Israel, Italy, Norway, Poland, Romania and Spain). It yielded 648 completed questionnaires and involved BA and MA student participants from 31 different cultural and linguistic backgrounds, with more than $75 \%$ being female students between the age of 18 and 25 . The survey delivery protocol was to present the questionnaire as an exercise in lexical meaning-retrieval and to administer it in class within 5-10 minutes in an early semester session (week 1 or week 2), i.e. before metaphor examples or theories were discussed. The aim of this practice was to reduce any inadvertent 'priming' effects for particular interpretations to a minimum, but given the diversity of delivery settings across institutions in ten countries, some priming effects of helpful explanations by the respective tutors cannot be completely ruled out. The diversity of delivery also led to a variation in length: some answers contained just one sentence, others included mini-essays of up to 250 words. Furthermore, the size of informant cohorts varied 
considerably, with only the Chinese, German and Italian responses numbering more than 100 each (see Appendix). These conditions ruled out any proper statistical analysis of the responses; however, a quantitative study was not the purpose of the pilot survey. More modestly, it aimed at finding out, in the first place whether and how much conceptual variation could be found and, secondly, whether any broad distribution patterns emerged that could be linked to culture-specific conceptual traditions, as hypothesised on the basis of the initial finding. The survey results thus only claim to represent heuristic evidence that prepares the ground for further, quantitatively validated studies.

In the first two years of delivery (exclusively at UEA, yielding 65 responses) the questionnaire task included the ambiguous formulation, "The concept of 'nation' can be described by way of a metaphor or simile that presents it in terms of a human body/person. Please apply this metaphor to your home nation $[\ldots]^{“}$. In all later versions delivered at UEA and other universities ( $=90 \%$ of the corpus), the source-concept indication was narrowed down to "in terms of a human body". Despite this change, $20 \%$ in both the initial group of respondents (presented with the ambiguous prompt) and the later group (asked only for NATION AS BODY) focused on a NATION-AS-PERSON reading, whereas the remaining $80 \%$ in both groups chose to focus on an interpretation of the NATION AS A PHYSICAL BODY. This result shows that for one fifth of informants, the NATION AS BODY metaphor seems to imply a NATION AS PERSON reading, which requires further investigation. In the present corpus, however, no linguistic or cultural factors could be associated with the choice between the BODY and PERSON variants: NATION AS PERSON answers are represented across all main national cohorts (see 3.2 below). As the BODY v. PERSON readings are semantically not identical and show a markedly distinct distribution in the pilot corpus, they are treated separately below. 


\subsection{Interpretations of the NATION-AS-BODY metaphor}

In contradiction to a possible over-interpretation of the findings from the initial class exercise, the survey showed that there was no exclusive set of interpretations in relation to specific linguistic/cultural groups; instead, there were clearly discernible distribution patterns. Thus, some British and US students' responses did include geography-based readings that were compatible with Chinese students' answers:

(9) London [...] can be considered as the 'head', directing operations as the brain does for the body. Birmingham, right in the centre of the country, could be said to act as the 'heart', controlling the flow of the 'blood' through the main arteries [...] [(US) English L1 informant]

(10) [...] Britain, a vast, churning body of 48 million people, sucking in resources, processing them, and spewing out fumes and ideas. The mouth and nose are Dover and Portsmouth, sucking in the oxygen of European food and produce. [(British) English L1 informant]

On the other hand, some Chinese students constructed function-focused BODY PARTINSTITUTION mappings that might be considered as typical of the Western body politic tradition, and added humorous innovative applications of their own as in (12):

(11) The communist party of China is the head of the body. It leads the functions of the whole body system [...]. The government is the nervous system of the body, which is controlled by the head of the body. [Mandarin L1 informant]

(12) Corrupt officials are like fine hairs on China's arm. They grow there, thus humiliate the beauty of a lady by showing the world how they feed on people. [...] Corrupt officials are hard to be got rid of just like the hairs, being shaved off but later appearing to your eyes again. [Mandarin L1 informant] 
However, responses such as (9)-(10) and (11)-(12) are each representative of only a third of the British/US v. Chinese interpretations of the NATION-AS-BODY metaphor respectively. For other European/“Western’ student cohorts with sufficiently many responses, the preponderance of the anatomy-/function-based reading over the geography-based interpretation was equal or even more pronounced as for the British/US cohorts (e.g., German: 15:1, Hungarian: 3:1, Israeli: 7:1, Italian: 3:1, Polish and Romanian: only anatomy-/function-based answers). Geography-based responses were recorded in a few questionnaires filled in by Japanese, Kurdish and French students, but their numbers are too low to allow a comparison. These results provide further evidence for contrastive preferences in interpretations of the NATION-AS-BODY metaphor between Chinese and nonChinese respondents. Two thirds of Chinese students' responses were geography-based, whereas most European, US and Israeli students are likely to reproduce parts of the 'Western' tradition of conceptualising the nation as a body in the sense of a functional whole that consists of hierarchically ordered members and organs.

How can we explain this variation in the conceptual grounding of interpretations of the NATION-AS-BODY metaphor? In Western culture(s), we can identify a tradition of explicit models of the NATION STATE AS A HUMAN-LIKE BODY in political philosophy and literary genres that forms a chain of intertextual references reaching back to the Renaissance and even the Middle Ages, which in turn builds on theological and philosophical traditions of Greek, Roman and Jewish-Christian Antiquity. It would need an equally extensive perspective on Chinese conceptual history to gauge the historical background of its conceptual, lexical and textual-discursive traditions of conceptualising the nation and compare it with the 'Western' model. Such an account is an urgent desideratum, as research on other Asian, i.e. Japanese, conceptual traditions has indicated 
that comparable but also very distinctive NATION-AS-BODY concepts existed in medieval times in these cultures (Shogimen, 2008).

There is also a relatively short-term historical influence in China's public discourse 'geobody' as part of its national identity since the mid- $20^{\text {th }}$ century that may be of relevance here. According to the political scientist W. Callahan (2009), Chinese visualizations of the nation's borders in maps since the 1950s have tended to convey a "Cartography of National Humiliation". Based on the historical experience of their nation having been the victim of repeated colonialist and imperialist attacks by foreign powers, cartography in the People's Republic of China routinely articulated fears of future territorial dismemberment, e.g. in a map from 1999 representing an "international conspiracy to divide up the PRC into a clutch of independent states" (Callahan, 2009, p. 143). More recently, the author contends, the politico-didactic goal of geopolitical maps in China has changed from "no longer primarily recover[ing] lost territory", but to symbolically “Anticipating the Unification of the Motherland.” (2009, p. 144). If geographical contours and locations are of such political import in the public sphere of China, a preference for grounding conceptualizations of its state organs and body parts in geo- and topologically based metonymies, which we observed in a two-thirds majority of Chinese students' responses, makes good sense.

In addition to providing corroborating evidence for distinguishing two main culturespecific tendencies in NATION-AS-BODY interpretations of the body politic metaphor, the questionnaire corpus revealed two further interpretation perspectives, which focused on (i) viewing the nation as part/organ of a larger body and (ii) configuring it as part of one's own personal body. The former perspective can be observed in examples (13) - (15) below, the latter in examples $(16)-(18)$ : 
(13) England is like an appendix, not very significant anymore but can still cause trouble and make you realise its [sic] there if it wants to [English L1 informant]

(14) Norway is a hand waving to the world. [Norwegian L1 informant]

(15) Italy is the leg of Europe. [Italian L1 informant]

Many examples of this type invoke folk-theoretical and symbolic knowledge as the conceptual grounding, e.g. in the above examples: appendix as 'superfluous' organ, handwaving as symbol of friendliness, the leg of Europe, which is closely linked to the stereotypical characterization of Italy as "Europe's boot" (Watts, 2009, p. 107). Other cases in which a nation is profiled against the background of the global community of nations include Germany as a fist (on account of the two World Wars), Israel as a fingernail (on account of its size and being at the receiving end of 'design changes' by outside powers), and China as the back of the world (on account of its stabilising function for the global economy).

The alternative 'nation-as-part-of $X$ ' version, i.e. NATION AS PART OF ONE's OWN BODY, is not present in some of the smaller national samples, but forms a recurring pattern across the Chinese, British and German cohorts. Half of these interpretations are sourced, as examples (16) - (18) show, from the notions of HEART and BLOOD as the centre or the chief medium of a person's identity, emotional existence and heritage:

(16) Motherland likes [sic, presumably intended: is like] my blood. Blood is a part of my body so that I can't live without blood, and I also can't live if I lost my motherland. What's more, motherland likes my blood [sic], because I feel its warmth and at the same time it provides me the 'oxygen' and 'nutrition'. [Mandarin L1 informant]

(17) The nation is the heart of each body, where feelings are. [Spanish L1 informant] 
(18) The nation is our blood, lungs and hearts. Nation is like the blood in the veins. Nation is like the heartbeating. [Hungarian L1 informant]

Other examples conceptualise the nation as one's own feet/legs (for "standing up and going forward in the world"), hands ("creating the people") or eyes ("noticing the democracy and equality enjoyed by general citizens as well as the corruptions and irresponsibility of some government parasites“").

These two interpretation perspectives of NATION AS PART OF SELF and NATION AS PART OF INTERNATIONAL/GLOBAL STRUCTURE also provide platforms for intricate and often humorous or ironical interpretations. They contrast with the two more frequently represented readings discussed above, i.e. the anatomy/function- and geography-based interpretations, which seem to be more standardised, repetitive and have only minimal explanations. These latter readings may thus be seen as representing the 'standard' or 'mainstream' applications of the body politic metaphor. By contrast, the less frequent NATION AS PART OF SELF and NATION PART OF INTERNATIONAL/GLOBAL STRUCTURE versions seem to have been produced mainly by students who were highly motivated to come up with imaginative answers. Nevertheless, these cases occur too often to be dismissed as wholly exceptional and they, too, can be linked to historical usage traditions. To associate the body politic with one's own physical body is conceptually close to the Western tradition of regarding the body politic as a mystical attachment to a monarch's personal body natural (Bertelli, 2001; Kantorowicz, 1997). Such links need to be explored further before any conclusions can be drawn about their significance for present-day metaphor understanding.

Overall, the widespread and at least partly systematic variation in the responses to metaphor interpretation tasks throws into question the assumption of an automatic and unconscious understanding of metaphors, which underlies early CMT literature. Doubtless, informants can interpret conventional metaphors very quickly and quasi-automatically when 
they are asked to come up with just one meaning and have been primed by source-related stimuli, as in much psycholinguistic research (Gibbs, 1994; Glucksberg, 2001, 2008). ;However, our survey seems to show that with open-ended questions and little priming, responses to metaphor interpretation tasks are much more varied, and the range of variation shows distribution patterns that can be linked to culture-specific traditions. Many CMTinspired analyses of 'automatic' metaphor comprehension have not paid much attention to culture-specific variation, as their main focus has been the refutation of earlier models that had hypothesised cognitively complex and time-consuming comprehension procedures of 'metaphor-as-indirect meaning' retrieval. This refutation was plausible for the understanding of conventional, 'entrenched' metaphors but also implied an assumption that only one target concept needed to be identified for the understanding task to be fulfilled. It is this unreflected assumption of one and only one 'correct' target concept that is put in question here, first on account of the surprising class exercise outcome (see section 1) and also by the much broader (though not statistically validated) database of the survey results. The NATION-AS-BODY metaphors elicited in our study clearly varied in their internal cognitive architecture (grounding, metaphor-metonymy combinations) and in their different applications (functional-anatomical, whole-part relationships), thus showing an even greater diversity than initially suspected. Such a wide range of variation makes no sense on the basis of assuming that metaphor understanding is always and only the automatic and unconscious of one identical target concept; instead, it supports the hypothesis of deliberate metaphor interpretation as part of a multi-step process of metaphorical meaning reconstruction.

\subsection{Interpretations of the NATION-AS-PERSON metaphor}


$20.2 \%$ of all responses (131 out of 648 ) focused on the PERSON concept as the source for the metaphorical conceptualisation of the NATION. The Chinese cohort provided the bulk of responses, but we also found examples from the German, Israeli, Italian, Norwegian, Romanian, Spanish and Polish cohorts. Like the BODY-based responses, the NATION-ASPERSON interpretations show recurring patterns that provide insights into culture-specific tendencies of metaphor interpretation. The majority of responses from the Chinese cohort list character traits or activities of PERSON TYPES, as in the following examples:

(19) Our nation is like a mother, who covers her children under her protection. China is like a giant person who moves forward step by step. China is a teenager still full of energy to do things. [...]. China is like an actor, who plays different roles on the world stage. [Mandarin L1 informant]

(20) China welcomes and gives warm hugs to foreigners who come to China. China is growing up day by day. China wears a beautiful dress to show her elegance to the whole world. [...] China kissed the India $[$ sic $]$ and comforted them in a very kind way. [Mandarin L1 informant]

Such depictions of one's home nation as a MOTHER or BEAUTIFUL WOMAN dominate the Chinese sample: they account for 46 interpretations out of a total of 70, 66 of which were given by female respondents. MOTHER or BEAUTIFUL WOMAN responses were also found in the Israeli, Italian, Polish, Romanian, Serbian, and Spanish samples but, curiously, not in the German or British ones. The latter do contain some FATHER characterizations, but the small number of occurrences ( 7 across the whole corpus) makes it impossible to discern specific socio-cultural trends. The main MALE figure in NATION-AS-PERSON characterisations is a WISE OLD MAN-(GRAND)FATHER-TEACHER figure who looks after his family as caringly as the MOTHER does. This person-type is represented across several national cohorts, as the following examples show: 
(21) Our nation is just like an old man, full of cultural deposits, he is also a good teacher who told us so many things. [Mandarin L1 informant]

(22) My nation looks like a 65 year old man, who is wise and clever but he hasn't be able to use his intelligence to become happy [...]. [Greek L1 informant]

(23) Britain is an easily likeable friend, $[\ldots][\mathrm{He}]$ is ancient but is experiencing revitalisation [...]. [English L1 informant]

(24) As Abraham Avinu [Abraham our father] signed an alliance between god [sic] and his body, so does the land of Israel and all of it's [sic] citizens with god [sic]. [Hebrew L1 informant]

This WISE, CARING FATHER/TEACHER figure collocates strongly with further person types that embody wisdom and competence (e.g., LAWYER, DOCTOR, PACIFIST), which are represented in 53 responses. By contrast, there are only two responses that come close to the STRICT FATHER model in the sense of Lakoff's depiction of conservative US morality ideology (Lakoff, 1996, 2004), both of which betray no great sympathy on the part of the respondent:

(25) My country is like a muscular, middle-aged man. He [...] has scarfs [sic] all over him, but still stands tall. He is white an [sic] catholic, but shows respect to others, [...] He has a strict facial expression, even if he tries to smile. [German L1 informant]

(26) My Government is like a selfish father. His "kids" are affected by his decisions without being asked. [...] [Spanish L1 informant]

Two related roles are those of FIGHTER/WARRIOR and GIANT ( 7 and 6 occurrences, respectively). However, they seem to be mainly motivated by the immediate topical and 
argumentative context of the respective answers: in the former case a focus on the nation's conflict with another nation, and for GIANT, a focus on China's territorial vastness.

Characterizations of one's own country as a BABY/CHILD only occur in responses by Chinese (9), Norwegian (2), Nigerian (1) and Belorussian students (1); they all relate at the target level to regained national statehood or economic/political strength. Overall, the corpus survey, especially the Chinese sample, is dominated by the picture of an EXTENDED FAMILY in which CARE, SOLIDARITY and COMPETENCE are of prime importance. This person type conforms to Lakoff's NURTURING PARENT model of political morality, as the alternative to the STRICT FATHER model $(1996,2004)$.

There is a small sub-group of NATION-AS-PERSON interpretations in terms of topical or historical political issues, which take a specific stance on these issues:

(27) Despite being a fairly young nation, Norway is already a full-grown petroholic. Like most addicts, Norway might appear well-functioning for longer periods of time [...] Still, Norway frequently turns into a state of denial. [Norwegian L1 informant]

(28) The Romanian nation [...] knows too well the price of hardship and [...] hard work has left deep marks on its soul. It [...] puts a lot of soul in everything it does. [...] It has not learnt yet that mind and reason should prevail over soul and heart. [Romanian L1 informant]

(29) The guts of the country remain from when we had an empire (think Elizabeth I). [= caption to 'stick man' representation of the body politic by English L1 informant]

In these examples, nation-specific experiences of historical change are reinterpreted as personality traits, with the NATION-AS-PERSON metaphor providing a platform for political comments. They resemble the second-order comments of some NATION-AS-BODY responses 
by Chinese students (see examples $7,8,19,20$ ) in exploiting the primary metaphor in order to achieve specific argumentative and ironical or ridiculing purposes. The increased length and complexity of such interpretations distinguishes them from the more 'immediate' responses, which may also contain a particular bias or perspectivisation, but only in a nutshell.

\section{Discussion}

The pilot survey has provided data about the understanding of political metaphor that appear to contradict several assumptions of a 1:1 match between the conventional(ised) meaning of a metaphor and its interpretative processing, such that the metaphor is only understood by accessing one 'correct' target concept (or not understood at all, or misunderstood). Instead, we found that the conventional, metaphorical idiom body politic was semantically reconstructed by both native and non-native speakers of ELF/ESL in various ways. In the first place, we found a fundamental distinction between NATION-AS-BODY and NATION-AS-PERSON perspectives, which has its origins in the semantic ambiguity of the phrase itself (as a result of its complex usage history) and in its presentation in the initial version of the questionnaire. In order not to skew the findings, we treated results for both versions separately and found a further four-way variation for NATION-AS-BODY and a more diffuse variation for NATION-ASPERSON. The former was dominated by the striking contrast between the two main preferred versions of corporeal conceptualisations of the nation, with Chinese responses favouring interpretations based on a geography-institution metonymy, whilst most 'Western' responses focused on the hierarchically ordered, anatomy- and function-based analogies to political institutions. In addition, two less frequent interpretation patterns emerged in the survey: conceptualization of the nation as an organ/part of a larger (international or global) body and 
its 'reverse' version, i.e. the understanding of the nation as part of the respondent's own body. Some of these latter response-types gave rise to elaborate interpretations that built on the BODY source concept to achieve further argumentative, polemical or ironic effects (e.g. England as appendix).

This latter perspective was even more relevant for the interpretations of the NATIONAS-PERSON metaphor. On the one hand we found evidence for the conceptualisation of the state as an AUTHORITY-FIGURE IN A FAMILY, with the great majority of responses focusing on the role of a NURTURING AND WISE PARENT in an EXTENDED FAMILY scenario who was stereotypically represented as MOTHER but also allowing for a male version. Again we found cases of elaborated interpretations that used the metaphor source as a platform for polemical or humorous comments on historical, political or social stereotypes about one's own nation.

In the light of these findings, the assumption of a naïve hearer/reader of metaphors who processes 'the' intended meaning automatically seems implausible, at least for figurative political discourse, where target concepts are frequently contentious and not narrowly defined. Our survey answers demonstrate that in this register metaphor processing is a complex, staged process (in the sense of Steen's Five Step model), which at the latter stages involves 'deliberate' choices between several meaning possibilities. The survey task highlighted and exposed this aspect by guiding the respondents to advance quickly to the stages of 'identification of analogical structure' and of 'cross-domain mapping', both of which imply deliberateness in the sense of demanding "mandatory attention to the fact that they are metaphorical" (Steen, 2011b, p. 84). The task itself thus made the deliberateness of metaphor interpretation inevitable but it did not predict the finding of substantial and systematic variation in the responses. If the responses had randomly associated BODY or PERSON aspects with the notion of the STATE, the survey results would be hard to interpret, but instead we observed distinct distribution patterns over a narrowly limited set of variants, some of which 
could be associated with culture-specific conceptual and discursive traditions. Due to the limitations of the pilot study, the respondents' awareness of such traditions (and its role in completeing the task) could not be ascertained.

Sub-sets of both the NATION-AS-BODY and NATION-AS-PERSON responses revealed a further dimension of interpretative deliberateness, namely argumentative and humorous elaborations of the basic metaphor to comment on topical or historical political issues. The sophistication and pragmatic exploitation of the basic metaphor that are required to caricature political institutions or agents as 'hair' or 'stomach ache', or as a 'selfish father' or 'petroaddict', all go beyond automatic interpretation and amount to mini-comments on the politics of the respective nations. They can best be explained as secondary, 'extra'- or 'super'deliberate reflections that build on the basic NATION-AS-BODY or -PERSON scenarios, to imply a strong polemical bias and in some cases read like the introduction to a complex political argument.

\section{Perspectives for future research}

This pilot study opens up a new arena for empirical research into the relationship between metaphor reception on the one hand and cultural context on the other. By concentrating on the reception/interpretation side, the findings complement existing research on culture-specific variation in metaphor production (Díaz Vera, 2014; Idström \& Piirainen, 2012; Kövecses, 2005; Musolff et al., 2014; Sharifian, 2014, 2015; Sharifian et al., 2008; Yu, 2008, 2015), effectively underlining its significance for a cognitive metaphor theory. The theoretical challenge posed by culture-specific variation of metaphors has its roots in their nature as both conceptual and embodied phenomena. Body-based experience forms a universal basis of our metaphorical mappings (Gibbs, 2005), but these conceptual mappings themselves are 
culturally acquired and transmitted. There are thus few, if any, 'purely' experiential (hence potentially universal) BODY-concepts, whereas the above-mentioned cross-cultural studies have demonstrated wide-spread and substantial variation in the use of body-organs and functions as source domains, e.g. for emotion- and person metaphors (BRAIN or HEART or BELLY as centre of emotions or personal identity). If our findings of interpretation preferences for NATION-AS-BODY and NATION-AS-PERSON across cohorts from diverse cultural traditions can be corroborated in future studies, they will contribute to our understanding of the emergence, dissemination and entrenchment of political stereotypes in the respective cultures. Specifically, they help to highlight the issue of hidden variation in figurative ESL/ELF usage, which may go unnoticed if the L2 metaphor formulations in question (here, body politic) are only analysed on the production side and learners are assumed to either succeed or fail in accessing only 'one' possible (supposedly correct) answer as intended by the speaker. Instead, interpretative variation and creativity seem to be characteristic for ESL/ELF usage contexts, as has been already indicated by a number of studies in the fast growing field of applied research on figurative L2-acquisition (see section 2 above). In our case, the learners were encouraged to deal with highly complex and cognitively rich political metaphors, which further enhanced such creativity, so that their metaphor interpretation task involved at least partly a metaphorical production/(re-)construction element. The precise delimitation of both elements and their respective weight in the complete figurative meaning retrieval process needs further empirical investigation.

Secondly, the study underlines the importance of deliberateness as a central issue of metaphor research, not just in production but also in reception/interpretation. This issue is not contradicted or made irrelevant by findings which show that metaphors can be produced and understood semi-automatically, i.e. without the users being aware of the metaphoricity of their language use/understanding or of the particular semantic motivation of specific metaphors. 
Such 'unconscious' metaphor processing is undoubtedly also involved in metaphor understanding (e.g. in the early stages of Steen's Five-Step process model). However, the fact that there is some unconscious processing does not preclude in any way the possibility of deliberate interpretation, which, as our pilot-survey has shown, can be triggered relatively easily and produce qualitatively rich results of significant culture-specific variation. Corroboration of these findings through validated quantitative studies, as well as through further qualitative research (e.g., by post-task interviews of respondents), should be the next step in the construction of a comprehensive model of metaphor reception and understanding.

\section{Acknowledgement}

I am especially indebted to colleagues and students at the universities of Aston, Birmingham and East Anglia in the UK, Heidelberg University (Germany), Eötvös Lorand University in Budapest (Hungary), the Universities of Estremadura and La Mancha in Spain, Hadassah College and the Hebrew University in Israel, the University of Verona (Italy), Oslo University (Norway), Kraków College "Stairways School of English" (Poland), the University of Bucharest (Romania), and Hangzhou Normal University in the People's Republic of China.

\section{References}

Bertelli, S. (2001). The king's body. Sacred rituals of power in medieval and early modern Europe. University Park, PA: Pennsylvania State University Press. 
Callahan, W. A. (2009). The cartography of national humiliation and the emergence of China's geobody. Public Culture, 21(1), 141-173.

Charbonnel, N. (2010). Comme un seul home. Corps politique et corps mystique. 2 vols. Lons Le Saunier: Aréopage.

Chilton, P. \& Lakoff, G. (1995). Foreign policy by metaphor. In C. Schäffner \& A. Wenden (Eds.), Language and peace. (pp. 37-55). Aldershot: Ashgate.

Deignan, A. (2011). Deliberateness is not unique to metaphor: A response to Gibbs. Metaphor and the Social World, 1(1), 67-69.

Díaz Vera, J. E. (Ed.). (2014). Metaphor and metonymy across time and cultures:

Perspectives on the sociohistorical linguistics of figurative language. Berlin/ Boston: De Gruyter Mouton.

Gibbs, R. W. (1994). The poetics of mind: figurative thought, language, and understanding. Cambridge: Cambridge University Press.

Gibbs, R. W. (2005). Embodiment and cognitive science. New York: Cambridge University Press.

Gibbs, R. W. (2011a). Are ‘deliberate' metaphors really deliberate? A question of human consciousness and action. Metaphor and the Social World, 1(1), 26-52.

Gibbs, R. W. (2011b). Advancing the debate on deliberate metaphor. Metaphor and the Social World, 1(1), 67-69.

Gibbs, R. W. and H. Colston (2012). Interpreting figurative meaning. Cambridge: Cambridge University Press.

Giora, R. (2003). On our mind: Salience, context, and figurative language. Oxford: Oxford University Press. 
Glucksberg, S. (2001). Understanding figurative language. From metaphors to idioms. With a contribution by M. S. McGlone. Oxford: Oxford University Press.

Glucksberg, S. (2008). How metaphors create categories - quickly. In R. W. Gibbs (Ed.). The Cambridge handbook of metaphor and thought (pp. 67-83). Cambridge: Cambridge University Press.

Guldin, R. (2000). Körpermetaphern: Zum Verhältnis von Politik und Medizin. Würzburg: Königshausen \& Neumann.

Hale, D. G. (1971). The body politic. A political metaphor in renaissance English literature. The Hague/Paris: Mouton.

Idström, A., \& Piirainen, E. (Eds.), in cooperation with Falzett, T. F. M. (2012). Endangered metaphors. Amsterdam: John Benjamins.

Kantorowicz, E. H. (1997). The king's two bodies. A study in medieval political theology. Princeton, NJ: Princeton University Press.

Kövecses, Z. (2000). Metaphor and emotion: Language, culture, and body in human feeling. Cambridge: Cambridge University Press.

Kövecses, Z. (2002). Metaphor: A practical introduction. Oxford: Oxford University Press.

Kövecses, Z. (2005). Metaphor in culture: Universality and variation. Cambridge: Cambridge University Press.

Lakoff, G. (1996). Moral politics: What conservatives know that liberals don't. Chicago, IL: University of Chicago Press.

Lakoff, G. (1993). The contemporary theory of metaphor. In A. Ortony (ed.). Metaphor and thought (2nd ed.) (pp. 202-251). Cambridge: Cambridge University Press. 
Lakoff, G. (2004). Don't think of an elephant! Know your values and frame the debate. The essential guide for progressives. Foreword by Howard Dean. White River Junction, VT: Chelsea Green Publishing.

Lakoff, G., \& Johnson, M. (1980/2003). Metaphors we live by. Chicago, IL: University of Chicago Press.

Littlemore, J., Chen, P., Koester, A. \& Barnden, J. (2011). Difficulties in metaphor comprehension faced by international students whose first language is not English. Applied Linguistics, 32(4), 408-429.

MacArthur, F., Littlemore, J., \& Krennmayr, T. (2013). SEEING is not just UNDERSTANDING: Sight metaphors in undergraduate office hours' consultations. Presentation, 3rd international conference on Meaning Construction, Meaning Interpretation: Applications and Implications (CILAP/CRAL). Logroño, Spain.

Müller, C. (2011). Are 'deliberate' metaphors really special? Deliberateness in the light of metaphor activation. Metaphor and the Social World, 1(1), 67-69.

Musolff, A. (2010). Political metaphor and bodies politic. In U. Okulska \& P. Cap (Eds.), Perspectives in politics and discourse (pp. 23-41). Amsterdam: John Benjamins.

Musolff, A. (2011). Metaphor in discourse history. In M. E. Winters, H. Tissari \& K. Allan (Eds.). Historical cognitive linguistics (pp. 70-90). Berlin/New York: De Gruyter Mouton.

Musolff, A. (2014). Metaphors: Sources for intercultural misunderstanding? International Journal of Language and Culture, 1(1), 42-59.

Musolff, A., MacArthur, F., Pagani, G. (Eds.) (2014). Metaphor and intercultural communication. London: Bloomsbury. 
Nacey, S. (2013). Metaphors in learner English. Amsterdam: John Benjamins.

Philip, G. (2010). "Drugs, traffic, and many other dirty interests": Metaphor and the language learner. In G. Low, Z. Todd, A. Deignan, \& L. Cameron (Eds.), Researching and applying metaphor in the real world (pp. 63-80). Amsterdam: John Benjamins.

Piquer-Piriz, A. M. (2010). Can people be cold and warm? Developing understanding of figurative meanings of temperature terms in early EFL. In G. Low, Z. Todd, A. Deignan \& L. Cameron (Eds.), Researching and applying metaphor in the real world (pp. 2134). Amsterdam: John Benjamins.

Pragglejaz Group (2007). MIP: A method for identifying metaphorically used words in discourse. Metaphor \& Symbol, 22, 1-40.

Sharifian, F. (2014). Conceptual metaphor in intercultural communication between speakers of Aboriginal English and Australian English. In A. Musolff, F. MacArthur \& G. Pagani (Eds.), Metaphor and intercultural communication (pp. 117-129). London: Bloomsbury.

Sharifian, F. (2015). Cultural linguistics: The development of a multidisciplinary paradigm. Language and Semiotic Studies, 1(1), 1-26.

Sharifian, F., Dirven, R., Yu, N., \& Niemeier, S. (Eds.). (2008). Culture, body, and language. Conceptualizations of internal body organs across cultures and languages. Berlin/ $\mathrm{New}$ York: Mouton de Gruyter.

Shogimen, T. (2008). Treating the body politic: The medical metaphor of political rule in late medieval Europe and Tokugawa Japan. The Review of Politics, 70, 77-104.

Steen, G. J. (2008). The paradox of metaphor: Why we need a three-dimensional model of metaphor. Metaphor and Symbol, 23(4), 213-241. 
Steen, G. J. (2009). From linguistic form to conceptual structure in five steps: Analyzing metaphor in poetry. In G. Brône \& J. Vandaele (Eds.), Cognitive poetics: Goals, gains, gaps (pp. 197-226). Berlin/New York: Mouton de Gruyter.

Steen, G. J., Dorst, A., Herrmann, B., Kaal, A., Krennmayr, T., \& Pasma, T. (2010). A method for linguistic metaphor identification: From MIP to MIPVU. Amsterdam: John Benjamins.

Steen, G. J. (2011a). What does 'really deliberate' really mean? More thoughts on metaphor and consciousness and action. Metaphor and the Social World, 1(1), 53-56.

Steen, G. J. (2011b). From three dimensions to five steps: The value of deliberate metaphor. metaphorik.de, 21, 83-110.

Wang, C., \& Dowker, A. (2010). A cross-cultural study of metaphoric understanding. In G. Low, Z. Todd, A. Deignan, \& L. Cameron (Eds.), Researching and applying metaphor in the real world (pp. 105-122). Amsterdam: John Benjamins.

Watts, M. T. (2009). Reading the landscape of Europe. Rochester, NY: Nature Study Guild Publishers.

Yu, N. (2008). Metaphor from body and culture. In R. W. Gibbs (Ed.), The Cambridge handbook of metaphor and thought (pp. 247-261). Cambridge: Cambridge University Press.

Yu, N. (2015). Embodiment, culture, and language. In F. Sharifian (Ed.), The Routledge handbook of language and culture (pp. 227-239). London: Routledge.

Author's address

Andreas Musolff 
University of East Anglia, School of Politics, Philosophy and Language and Communication, Norwich, NR4 7TJ

Norfolk, UK

a.musolff@uea.ac.uk

\section{Biographical note}

Andreas Musolff graduated from Düsseldorf University and is Professor of Intercultural Communication at the University of East Anglia in Norwich (UK). His research interests include the pragmatics of intercultural and multicultural communication, metaphor studies and public discourse. His publications include Metaphor and Political Discourse (2004), Metaphor, Nation and the Holocaust (2010), and (co-edited) Metaphor and Intercultural Communication (2014).

Appendix: Linguistic/cultural Backgrounds of Questionnaire Respondents

\begin{tabular}{|l|l|}
\hline Linguistic/Cultural background & Number of Participants \\
\hline Albanian & 1 \\
\hline Arabic & 7 \\
\hline Bemba & 1 \\
\hline Chinese (Mandarin + Cantonese) & 156 \\
\hline Dutch & 1 \\
\hline English (UK) & 36 \\
\hline English (US) & 6 \\
\hline Estonian & 1 \\
\hline French & 3 \\
\hline German & 114 \\
\hline Greek & 1 \\
\hline Hebrew & 34 \\
\hline Hungarian & 23 \\
\hline Indonesian & 1 \\
\hline Iranian (Farsi) & 2 \\
\hline Italian & 119 \\
\hline Japanese & 4 \\
\hline
\end{tabular}




\begin{tabular}{|l|l|}
\hline Korean & 1 \\
\hline Kurdish & 2 \\
\hline Latvian & 1 \\
\hline Lithuanian & 1 \\
\hline Norwegian & 5 \\
\hline Polish & 16 \\
\hline Portuguese & 1 \\
\hline Romanian & 64 \\
\hline Russian & 2 \\
\hline Serbian & 1 \\
\hline Spanish & 40 \\
\hline Turkish & 2 \\
\hline Ukrainian & 1 \\
\hline Yoruba & 1 \\
\hline Overall & $\mathbf{6 4 8}$ \\
\hline
\end{tabular}

